\title{
CENTRAL AUTONOMIC PHARMACOLOGY OF THYROTROPIN RELEASING HORMONE
}

\author{
Anna-Leena Sirén and Giora Feuerstein \\ Neurobiology Research Division, Department of Neurology \\ Uniformed Services University of the Health Sciences \\ 4301 Jones Bridge Road, Bethesda, MD 208144799
}

\section{Introduction}

Thyrotropin releasing hormone (TRH, 1-pyroglutamyl-1-histidyl-1-prolinamide) was the first hypothalamic releasing substance to be isolated, chemically characterized and synthetized $/ 1 /$. The studies to date have revealed that the thyrotropin release from the pituitary gland is only one of the numerous actions of TRH. In addition to its endocrine actions (TSH and prolactin release) this tripeptide has central nervous system actions totally unrelated to its effects on the hypothalamo-pituitary axis. This review aims to summarize the studies on the central nervous system actions of TRH with special emphasis on the autonomic pharmacology of this peptide.

\section{TRH and its Receptors in the Central Nervous System}

TRH-like immunoreactivity is widely distributed throughout the whole nervous system of vertebrates including man, guinea pig, rat, mouse and frog. TRH is also present in plants and in lower animals which totally lack the thyroid functions. Moreover, over $70 \%$ of the total central nervous system TRH is located outside the hypothalamus, although the highest local concentrations of TRH in the brain are found in the hypothalamus and pituitary gland. Outside the nervous system, relatively high levels of TRH are found in the gastrointestinal system (for review 1,2).

Both hypothalamic and extrahypothalamic brain synaptosomes contain high amounts of TRH immunoreactivity. Furthermore, TRH has been shown to be present in nerve endings. In brain synaptosomes, fragments and slices, in vitro TRH is both released and taken up /1,2/. Furthermore, TRH was shown to be colocalized with neurotransmitters such as 5-hydroxytryptamine (5-HT) and substance $P$ in the rat brain $/ 3 /$. More recent studies indicate that TRH arises from the post-translational cleavage of a large precursor protein of 123 amino acids $/ 4 /$. In the rat brain both TRH and pro-TRH have been found in 
neuronal perikarya of the parvocellular division of the paraventricular nucleus of the hypothalamus and the raphe complex of the medulla $/ 5 /$. The distribution of TRH receptors is limited to relatively few tissues such as brain, pituitary, retina and spinal cord $/ 1 /$. Burt and Snyder $/ 6 /$ were the first to demonstrate the stereospecific binding of ${ }^{3}[\mathrm{H}] \mathrm{TRH}$ to rat brain and to establish high and low affinity binding sites. Recently, TRH-receptors have been shown to be present also in human brain and spinal cord $/ 7,8 /$. Autoradiographic studies in the rat brain have revealed that high levels of TRH receptors are found in the rhinencephalon, including accessory olfactory bulb, nuclei of amygdala and hippocampus; moderate to low levels were found in thalamus and hypothalamus and in most regions of the rhombencephalon 19-12/. Although comparisons of the distribution of TRH receptors to TRH immunoreactivity indicates that in most brain areas there is little obvious correlation between levels of TRH peptide and its receptors, the extensive distribution of TRH receptors in the CNS provides an explanation for the variety of behavioral and autonomic effects observed when TRH is administered into the brain.

\section{Behavioral and Neurological Effects}

In experimental animals TRH has an an analeptic effect and antagonizes narcosis induced by a variety of CNS depressant agents such as ethanol, barbiturates and ketamine. Other typical effects of TRH are forepaw tremor, "wet dog shakes," alert appearance and overall arousal /13-15/.

In some studies TRH has been shown to have amphetamine-like actions (reduction in operant tasks and eating behavior). Increased locomotor activity by centrally administered TRH was first shown by Plottnikoff $/ 16 /$. This effect is antagonized by haloperidol or pimozide $/ 17 /$, suggesting that dopamine receptors in mesolimbic system mediate this effect of TRH. However, TRH has not been shown to have any effect on dopamine or amphetamine induced circling behaviour in unilaterally nigrostriatal lesioned rats $/ 18 /$. In microiontophoretic studies TRH has been reported to enhance the effects of acetylcholine on cortical neurons /19/.

The analeptic effect and arousal induced by TRH in experimental animals led to the hypothesis that this peptide might have some beneficial effects in human depression. In the early seventies, intravenously injected TRH was shown to have "antidepressant" effects in human depression $/ 20,21 /$. In experimental animals antidepressant drugs have been shown to cause increased release of TRH in brain tissue ex vivo /22/. The therapeutic activity of antidepressant drugs, on the other hand, has been related to their effect on 
5-HT neurotransmission /23/. Since TRH is colocalized with 5-HT in the brain and reported to have some beneficial effect on depression in man, it might act as a comodulator of 5-HT which causes adaptive changes in 5-HT neurotransmission. However, clinical investigations with TRH have attempted to establish its use in depression but in no case have the results proved decisive $/ 13,24 /$. Other mental disorders where TRH has been tried clinically include schizophrenia and alcohol withdrawal /13,24/.

TRH increases skeletal muscie tonus in experimental animals probably by a direct action on spinal motor neurons $/ 19,25 /$. In the rat spinal cord motoneurons TRH has been shown to coexist with 5-HT and substance $\mathbf{P}$ $/ 1,3 /$ and in lumbar spinal motoneurons of urethane-anesthetized rats 5-HT, substance $\mathbf{P}$ and TRH were recently shown to enhance both glutamate and asparatate-induced excitation of the motoneurons $/ 26 /$.

Intravenously injected TRH has been proven to be of benefit in reducing weakness and spasticity in motoneurone disease and in promoting recovery in both motoneurone disease and spinal trauma /27-29/. These effects were postulated to be mediated primarily by stimulation of TRH receptors in spinal cord, but spinal hypertension and increased blood flow after spinal injury were also suggested to contribute to the therapeutic effect of TRH. Other neurological disorders where TRH has been tried as treatment include Parkinson's disease and childhood hyperactivity with varying improvement in these clinical conditions /24/.

\section{Thermoregulation}

Central nervous system administration of TRH or its stable analogs antagonizes reserpine-induced hypothermia. In intact animals, depending on the species, ambient temperature and the route of administration, TRH might produce hypothermia or hyperthermia. One of the main metabolites of TRH in the body, histidyl-proline-diketopiperazine, has been reported to antagonize the TRH-induced hyperthermia in the rat $/ 30 /$. For a more detailed review over the issue see Horita et al. /14/ and Metcalf /13/.

\section{Gastrointestinal Effects}

TRH increases colonic and duodenic activity and gastric acid secretion by a central nervous system activation of parasympathetic outflow. In vitro TRH has been shown to stimulate the guinea pig ileum and rat antrum, pyloric sphincter and colon but the significance of these effects is not clear. Since moderate levels of TRH immunoreactivity are found in the gastrointestinal 
system, this peptide might have a physiological role in regulation of gastric and intestinal motility. For further details see recent reviews by Horita et al. /14/, Morley /24/ and Prasad /1/.

\section{Respiratory Effects}

Central nervous system administration of TRH produces increases in ventilatory rate $/ 31,32 /$ and respiratory minute volume with no change in tidal volume $/ 31 /$. In halothane anesthetized rats, depletion of serotonin with pargyline and 5,7-dihydroxy-tryptamine attenuated the tachypnea induced by TRH intracerebroventricularly (icv) as well as neonatal treatment with capsaicin or acute vagotomy in adult rats /33/. Moreover, the supersensitivity of serotonin depleted rats to TRH was shown to be a result of an elevated $\mathrm{PCO}_{2}$, thus suggesting that the respiratory responses to exogenous TRH can depend partly on afferent vagal input, but that other endogenous inputs to the respiratory center such as $\mathrm{CO}_{2}$ also contribute to the magnitude of the observed response by non-vagal routes. TRH immunoreactivity has been found in respiratory division of nucleus tractus solitarius (NTS) /34/. It was recently reported $/ 35 /$ that in a pig brainstem preparation in vitro TRH induced rhythmic bursting of neurons in the respiratory division of NTS. On the other hand, it was shown recently that intravenous injection of TRH inhibited the leukotriene $\mathrm{D}_{4}$-induced bronchoconstriction in the guinea pig 136/. This might have some contribution to the beneficial effect of TRH in anaphylactic shock (see below).

\section{Cardiovascular Effects}

TRH has a well documented pressor effect in both experimental animals $\mid 32,37-40 /$ and in man $/ 41-44 /$. In animals the TRH-induced increment in blood pressure is accompanied by a tachycardia, while in humans the heart rate does not significantly change after TRH-administrations. These cardiovascular actions of TRH are likely to be mediated via central nervous system since more than a thousand fold higher doses are needed to induce cardiovascular changes after systemic administrations /28/ than after injections into the brain ventricles or distinct brain nuclei $/ 40,45,46 /$. Moreover, transections in the cervical spinal cord abolished the pressor response to icv injected TRH in the rabbit, while spinal transections below $T_{1}$ had no influence on TRH-induced hypertensive action $/ 38 /$. The pressor effect of TRH in leukotriene $\mathrm{D}_{4}$-induced hypotension is also totally abolished in the pithed rat in which the total central nervous system has been destroyed $/ 47 /$. 
The site of the cardiovascular actions of TRH in the brain is not known. Feuerstein and co-workers /40/ injected subnanamolar doses of TRH into the nucelus preopticus medialis (POM) of hypothalamus in the conscious rat and found increases in both blood pressure and heart rate. Microinjections of picomolar amounts of TRH into different hypothalamic regions of halothane anesthetized rats were also shown to elicit moderate changes in mean arterial pressure and heart rate with no changes in respiratory rate or body temperature 145/. However, the doses of TRH used in these studies are high enough to elicit increments of blood pressure and heart rate also after icv administration $/ 32,46 /$. A recent report by Paakkari et al. /48/ suggests that the pressor effect of TRH arises from the region of the fourth ventricle whereas the cardio-accelerator effect is likely to be mediated by activation of some forebrain structures. This suggestion is contradicted by the earlier findings $/ 40 /$ that TRH, microinjected into the NTS, produced a brief depressor effect on blood pressure and a delayed increase in heart rate.

Although the pressor and tachycardic effects of TRH have been well characterized, little is known about the hemodynamic changes mediating these gross cardiovascular changes. In anesthetized rabbits a systemic injection of TRH has been shown to increase cerebral blood flow /49/. By using the directional ultrasound Doppler technique we recently reported a differential regional blood flow pattern after both subnanomolar doses of TRH icv as well as by a high systemic dose /46/: The blood flow to skeletal muscles significantly increased while the renal (and to a lesser degree the mesenteric) blood flow dose-dependently decreased after TRH injections. The pattern of these blood flow changes resembled those induced by intravenous injection of epinephrine, suggesting that these effects might be mediated by the activation of the sympatho-adrenomedullary axis. We have also shown that in the conscious rat the increase in blood pressure by TRH is likely to be due to an increase in cardiac output, while due to the differential blood flow changes the total peripheral resistance remains unchanged in intact rats $/ 46 /$.

Concomitantly with the increments in blood pressure and heart rate, TRH induces increase in plasma catecholamines in both animals $/ 40,50 /$ and man 142/. These findings led to the suggestion that the cardiovascular effects of TRH are mediated by an activation of sympathetic outflow. The pressor effect of TRH icv in rat endotoxic shock has been shown to be abolished by adrenal demedullectomy $/ 51 /$. In conscious intact rats the tachycardic effect of TRH injected into the POM was also blocked and the pressor response somewhat reduced in bretylium treated adrenal demedullated rats $140 /$. Studies in progress in our laboratory have shown that the renal vasoconstrictor response to icv or iv administered TRH is reduced to about 50\% in adrenal 
demedullated rats while the increase in skeletal muscle blood flow is blocked only after bretylium treatment, suggesting that both the catecholamine release from adrenal medulla and the activation of sympathetic nerves contribute to these actions of TRH. However, some non-adrenergic mechanisms are also likely to be involved in the cardiovascular actions of TRH, since its effects on blood pressure and heart rate were not affected by pretreatments with ganglion blockers, reserpine, phentolamine or propranolol $/ 52,38$, and unpublished results of our laboratory/. This suggestion is further supported by the recent clinical findings that the rise in blood pressure by intravenous TRH in humans is not accompanied with any changes in plasma catecholamines 144/. Since measuring plasma catecholamines only might not be a good index of sympathetic tone, these findings do not exclude the role of sympathetic activation in the effects of TRH,

In addition to the sympathetic nervous system other pressor systems have been related to the cardiovascular effects of TRH. Central nervous system administration of TRH caused increments in plasma levels of vasopressin in rabbits /52,53/ but had no effect on plasma vasopressin in dogs /54/. We found only slight and biologically insignificant increases in plasma vasopressin after system administration of TRH in conscious rats. Moreover, Horita et al. 152/ have shown that the TRH-induced increase in vasopressin can be differentiated from its hypertensive effect; hexamethonium blocked the increment of plasma vasopressin but not the pressor response to icv administered TRH in anesthetized rabbits. It was recently found that the pressor effect of TRH icv in urethane-anesthetized rats is not blocked by a vasopressin antagonist $/ 55 /$.

Another pressor system which has been related to the cardiovascular actions of TRH is the renin-angiotensin system. The pressor effect of icv administered TRH was attenuated by treatment with the angiotensin converting enzyme inhibitor captopril or with the angiotensin receptor antagonist $155 /$. However, the endogenous renin-angiotensin system plays hardly any role in the effects of TRH, since administrations of this peptide to either humans /42/ or rats (unpublished observation of our laboratory) had no effect on plasma renin activity.

\section{TRH in Shock and Trauma}

Since TRH has been shown to be a potent cardiotonic and respiratory stimulator it was only natural to assume that such a compound might have therapeutic potential in cardiovascular states in which respiratory, cardiac or hemodynamic variables are severely depressed. This suggestion was further 
supported by experiments showing that TRH effectively blocks opiates and opioid peptides mediated effects /56/; since activation of the endogenous opioid system has been argued to play an important role in cardiovascular depression following various shock stimuli $/ 56 /$, antagonism of opioid mediated cardiovascular depression by TRH was considered an additional mechanism for the potential beneficial actions of TRH in shock states $/ 56 /$.

The potential therapeutic capacity of TRH was examined in several shock and trauma situations: hemorrhage, endotoxemia, anaphylaxis, spinal cord injury and multiple organ trauma.

In hemorrhagic shock, original studies by Holaday et al./57/ demonstrated that TRH can reverse the systemic hypotension produced by bleeding. The pressor response to TRH in hypovolemic hypotension was confirmed in other studies $158,59,60 /$. In a study conducted on anesthetized, cynomolgus monkeys, TRH was shown to increase myocardial contractility after hemorrhage 159/. Moreover, in the anesthetized rat exposed to severe bleeding TRH was shown to increase cardiac output along with mean arterial pressure $160 /$. However, in none of the studies cited above did TRH improve the survival rate of various experimental animals exposed to hemorrhagic shock; in a more recent study it was shown that TRH decreased the survival rate of conscious rats exposed to hypovolemic hypotension, a phenomenon most probably related to the substantial reduction in essential organ blood flow due to increase in vascular resistance $/ 60 /$. Thus, the beneficial effect of TRH in hemorrhagic shock or other forms of hypovolemic hypotension is doubtful and extreme caution should be exercised in extrapolating the early reports on pressor effects of TRH in hemorrhage to therapeutic efficacy in both experimental animals and humans.

A totally different form of shock is lipopolysaccharide (LPS) endotoxemia. In this form of shock the intracellular volume is primarily preserved yet cardiac depression, pulmonary hypertension and organ blood flow are severely deranged. In LPS endotoxemia, TRH was shown to produce a pressor response $157,61,62 /$. However, in this form of shock, short term survival (2 hours) was found to be improved by TRH treatment but this effect was not dose dependent. In a study conducted on cynomolgus monkeys, TRH treatment failed to improve survival in severe endotoxemia in spite of a substantial pressor effect $/ 62 /$. Further experiments are necessary to determine whether or not TRH might have a role in treatment of endotoxic shock.

Anaphylactic shock is still another form of shock which is mediated by specific immune response cells and mediators such as leukotrienes, histamine, PAFacether and others (for review see 63). The anaphylactic shock is 
characterized by severe hemodynamic derangements which include cardiac depression, hypotension and shock. TRH has been shown to reverse anaphylactic shock in the mouse $/ 64,65 /$ or guinea pigs $/ 66 /$; in the mouse, TRH substantially improved the survival rate in anaphylactic shock $/ 64 /$. The beneficial effect of TRH in this form of shock was atrributed to central activation of the sympatho-adrenomedullary system, primarily through $\beta_{1}$-adrenergic receptors $/ 64,65 /$. Furthermore, the therapeutic effect of TRH in anaphylactic shock might also be the result of improved pulmonary functions due to alleviation of the bronchoconstriction /36/. TRH was also shown to reverse the shock syndrome produced by the specific shockpromoting mediators of anaphylaxis such as leukotrienes $\mid 67-69,47 /$ or platelet activating factor, PAF-acether $/ 70 /$. In both shock paradigms, which were conducted on conscious rats or guinea pigs, the effect of TRH on survival rate was not examined. Thus, more definitive experimental work is necessary to determine whether TRH has significant therapeutic potential in immune reaction mediated shock states.

TRH was also utilized for therapeutic trials in several traumatic injury models. In multiple trauma models of the rat, TRH was found to exacerbate the shock state and decrease survival rate $158 /$. However, in a more discrete model of trauma, cervical spinal cord injury, TRH was found to improve long term neurologic recovery $/ 28,29 \%$. However, additional experimental work would be necessary to substantiate this report, especially in more clinically applicable models. It should be pointed out that although TRH was found to reduce blood flow in essential organs of oligemic rats $/ 60 /$, it was also shown that systemic administration of TRH to anesthetized rabbits increases blood flow to many brain regions $/ 49 /$. Thus, it might be possible that critical levels of blood flow to injured CNS zones might be preserved. This suggestion is contradicted, however, by the findings that TRH had no beneficial effect on ischemia induced by air embolization in experimental stroke in dogs $/ 71 /$.

In summary, although preliminary experimental work raised hopes and expectations for therapeutic usage of TRH in a variety of states of shock and trauma, the present situation is clearly controversial.

\section{Acknowledgements}

This work was supported in part by USUHS Protocols No. RO9211 and R09232. The opinions or assertions contained herein are the private ones of the authors and are not to be construed as official or reflecting the view of the Department of Defense or the Uniformed Services University of the Health Sciences. The authors wish to thank Ms. Wanda Patterson for her help in the preparation of this manuscript. 


\section{REFERENCES}

1. Prasad C. Thyrotropin releasing hormone. In: Lajtha A, ed, Handbook of Neurochemistry. Plenum Publishing Corporation, 1985; 175-200.

2. Palkovits $M$. Distribution of neuropeptides in the central nervous system: a review of biochemical mapping studies. Prog Neurobio 1984; 23: 151-189.

3. Shariff NA. Diverse roles of thyrotropin releasing hormone in brain, pituitary and spinal function. TIPS $1985 ; 119-122$.

4. Rupnow JH, Hinkle PM, Dixon JE. A macromolecule which gives rise to thyrotropin releasing hormone. Biochem Biophys Res Comm 1979; 89(2): 721-728.

5. Jackson IMD, Wu P. Immunohistochemical localization in the rat brain of the precursor for thyrotropin releasing hormone. Science 1985; 229: 1097-1099.

6. Burt DR, Snyder SH. Thyrotropin releasing hormone (TRH) apparent receptor binding in rat brain membranes. Brain Res 1975; 93: 309-328.

7. Manaker S, Winokux A, Rhodes CH, Rainbow TC. Autoradiographic localization of thyrotropin releasing hormone (TRH) receptors in human spinal cord. Neurology $1985 ; 35: 328-332$.

8. Winokur A, Manaker S, Eichen A, Rhodes CH, Rainbow TC, Autoradiographic localization of thyrotropin-releasing hormone (TRH) receptors in human brain. Soc Neurosci Abstr 1985; p. 901.

9. Manaker S, Winokur A, Rostene WH, Rainbow TC. Autoradiographic localization of thyrotropin releasing hormone receptors in the rat central nervous system. J Neurosci $1985 ; 5(1): 167-174$.

10. Mantyh PW, Hunt SP. Thyrotropin releasing hormone (TRH) receptors: localization by light microscopic autoradiography in rat brain using $\left[{ }^{3} \mathrm{H}\right]\left[3-\mathrm{Me}-\mathrm{His}^{2}\right.$ ]TRH as the radioligand. J Neurosci 1985; 5(2): 551-561.

11. Rostene WH, Morgat J-L, Dussaillant M, Rainbow TC, Sarrieau A, Vial M, Rossekin G. In vitro biochemical characterization and autoradiographic distribution of ${ }^{3} \mathrm{H}$-thyrotropin releasing hormone binding sites in rat brain sections. Neuroendocrinology 1984; 39: 81-86.

12. Shariff NA, Burt DR. Visualization and identification of TRH receptors in rodent brain by autoradiography and radioreceptor assays: focus on amygdala, $N$. accumbens, septum and cortex. Neurochem Int 1985; 7(3): 525-532.

13. Metcalf G. Regulatory peptides as a source of new drugs - the clinical prospects for analogues of TRH which are resistant to metabolic degradation. Brain Res Rev 1982; 4: 389-408.

14. Horita A, Kalivas PW, Simasko SM. Thyrotropin releasing hormone (TRH): possible physiological functions not related to the neuroendocrine system. Rev Pure Appl Pharmacol Sci 1983; 4(2): 111-137.

15. Griffiths EC. Thyrotropin releasing hormone: endocrine and central effects. Psychoneuroendocrinology 1985; 10(3): 225-235.

16. Plotnikoff NP, Prange AJ, Breese GR, Wilson IC. Thyrotropin releasing hormone: enhancement of DOPA activity by a hypothalamic hormone. Science 1972; 178: 417418.

17. Miyamoto $M$, Nagawa $Y$. Mesolimbic involvement in the locomotor stimulant 
action of thyrotropin releasing hormone (TRH) in rats. Europ J Pharmacol 1977; 44: 143-153.

18. Heal DJ, Green AR. Administration of thyrotropin releasing hormone in rats releases dopamine in the $\mathrm{N}$. accumbens but not $\mathrm{N}$. caudatus. Neuropharmacology 1979; 19: 23-31.

19. Yarbrough GC. On the neuropharmacology of thyrotropin releasing hormone (TRH), Prog Neurobio 1979; 12: 291-312.

20. Prange AJ, Wilson IC, Lara PP, Alltop LB, Breese GR. Effects of thyrotropin releasing hormone in depression. Lancet $1972 ; 2: 99-100$.

21. Kastin AJ, Ehrensing RH, Schalch DS, Anderson MS. Improvement in mental depression with decreased thyrotropin response after administration of thyrotropin releasing hormone. Lancet $1972 ; 2: 740-742$.

22. Lighton C, Bennett GW, Marsden CA. Increase in levels and ex vivo release of thyrotropin releasing hormone (TRH) in specific regions of the CNS of the rat by chronic treatment with antidepressants. Neuropharmacology $1985 ; 24(5): 401-406$.

23. Fuxe K, Orgen S-O, Agnati LF, Benefenati F, Fredholm B, Andersson K, Zini I, Encroth $P$. Chronic antidepressant treatment and central 5-HT synapses. Neuropharmacology $1983 ; 22: 389-400$.

24. Morley JE. Extrahypothalamic thyrotropin releasing hormone (TRH) - its distribution and its functions. Life Sci 1979; 25: 1539-1550.

25. Cooper BR, Boyer CE. Stimulant action of thyrotropin releasing hormone on cat spinal cord. Neuropharmacology 1978 ; 17: 153-156.

26. White SR. A comparison of the effects of serotonin, substance $P$ and thyrotropin releasing hormone on excitability of rat spinal motoneurons in vivo. Brain Res $1985 ; 335: 63-70$.

27. Engel WK, Siddique T, Nicoloff JT. Effect of weakness and spasticity in amyotrophic lateral sclerosis of thyrotropin releasing hormone. Lancet 1983; i: 73-75.

28. Faden AI, Jacobs TP, Holaday JW. Thyrotropin releasing hormone improves neurologic recovery after spinal trauma in cats. New Engl 3 Med 1981; 305: 1063-1067.

29. Faden AI, Jacobs TP, Smith MT, Holaday JW. Comparison of thyrotropin releasing hormone (TRH), naloxone and dexamethasone treatments in experimental spinal injury. Neurology $1983 ; 33(6)$ : 673-678.

30. Prasad C, Matsui T, Williams J, Peterkowsky A. Thermoregulation in rats: opposing effects of thyrotropin releasing hormone and its metabolite histidyl-proline-diketopiperazine. Biochem Biophys Res Comm 1978; 5: 1582-1587.

31. Hedner $J$, Hedner $T$, Jonason $J$, Lundberg $D$. Central respiratory stimulant effect by thyrotropin releasing hormone in the rat. Neurosci Lett 1981;25:317-320.

32. Koivusalo F, Paakkari I, Leppaluoto J, Karppanen $H$. The effect of centrally administered TRH on blood pressure, heart rate and ventilation in rat. Acta Physiol Scand 1979; 106: 83-86.

33. Mueller RA, Towle AC, Breese GR. The role of vagal afferents and carbon dioxide in the respiratory response to thyrotropin releasing hormone. Reg Peptides 1985; 10: 157-166.

34. Hokfelt $T$, Fuxe $K$, Johansson $O$, Jeffcoate $S$, White N. Thyrotropin releasing 
hormone (TRH)-containing nerve terminals in certain brain stem nuclei and in the spinal cord. Neurosci Lett 1975; 1: 133-139.

35. Dekin MS, Richerson GB, Getting PA. Thyrotropin releasing hormone induces rhythmic bursting in neurons of the nucleus tractus solitarius. Science 1985; 229: 67-69.

36. Kitao $\mathrm{T}, \mathrm{Koshino} \mathrm{T}$. Inhibition of leukotriene $\mathrm{D}_{4}$ bronchoconstriction in guinea pigs by thyrotropin releasing hormone. IRCS Med Sci 1985; 13: 983-984.

37. Beale IS, White RP, Huang S-P. EEG and blood pressure effects of TRH in rabbits. Neuropharmacology $1977 ; 16: 499-506$.

38. Horita A, Carino MA. Centrally administered TRH produces a vasopressin response in rabbits. Proc West Pharmacol Soc 1977;1 20: 303-304.

39. Eriksson L, Gordin A. Cardiovascular and behaviotal changes after ICV infusion of TRH in the conscious goat. Pharmacol Biochem Behavior 1981; 14: 901-905.

40. Feuerstein G, Hassen AH, Faden AI. TRH: cardiovascular and sympathetic modulation in brain nuclei of the rat. Peptides $1983 ; 4: 617-620$.

41. Abplanalp VHA. Hamodynamische effekte nach intravenoser applikation von thyrotropin releasing hormone. Arzneim-Forsch (Drug Res) 1976; 22(2): 71-277.

42. Morley JE, Tuck ML, Mayes DM, Rosenblatt S, Hershman JM. Thyrotropin releasing hormone increases plasma norepinephrine in man. Hormone Res 1981; 14: 18-23,

43. Borowski GD, Garofano CD, Rose LI, Levy RA. Blood pressure response to thyrotropin releasing hormone in euthyroid subjects. J Clin Endocrin Metab 1984; 58(1): 197-200.

44. Zaloga GP, Chernow B, Zajtchuk R, Chin R, Rainey TG, Lake Cr. Diagnostic dosages of protirelin (TRH) elevate BP by noncatecholamine mechanisms. Arch Intern Med 1984; 144: 1149-1152.

45. Diz DI, Jacobowitz DM. Cardiovascular effects produced by injections of thyrotropin releasing hormone in specific preoptic and hypothalamic nuclei in the rat. Peptides 1984; 5: 801-808.

46. Siren $A-L$, Feuerstein $G$. Effect of thyrotropin releasing hormone on blood pressure and peripheral blood flow in conscious rats. Fed Proc 1985; 44: 721.

47. Feuerstein G, Zukowska-Grojec Z, Bayorh M, Kopin IJ, Faden AI. Leukotriene $\mathrm{D}_{4}$-induced hypotension is reversed by thyrotropin releasing hormone. Prostglandins 1983; 26(5): 711-724.

48. Paakkari I, Nurminen M-L, Sirén A-L. Cardioventilatory effects of TRH in anesthetized rats; role of the brainstem. Eur J Pharmacol 1986; 122; 131-134.

49. Koskinen $L-O$, Bill $A$. Thyrotropin releasing hormone (TRH) causes sympathetic activation and cerebral vasodilation in the rabbit. Acta Physiol Scand 1984; 122: 127-136:

50. Brown MR. Thyrotropin releasing hormone: a putative CNS regulator of the autonomic nervous system. Life Sci 1981; 28: 1789-1795.

51. Holaday JW, Faden AI. Thyrotropin releasing hormone: autonomic effects upon cardiorespiratory function in endotoxic shock. Regulatory Peptides 1983; 7: 111-125.

52. Horita A, Carina MA, Weitzman RE. Role of catecholamine and vasopressin release in the TRH-induced vasopressin response. In: Usdin E, Kopin IJ, Barchas J, eds, 
Catecholamines: Basic and Clinical Frontiers, Vol. 2. New York: J. Barches, 1979; 1140-1142.

53. Weitzman RE, Firemark HM, Glatz TH, Fisher DA. Thyrotropin releasing hormone stimulates release of arginine vasopressin and oxytocin in vivo. Endocrinology 1979; 104(4): 904-907.

54. Huffman LJ, Campbell GT, Gilmore JP. Renal function and pituitary hormone release during cerebral osmostimulation and TRH in dogs. Peptides 1983; 4: 843-847.

55. Mattila J, Bunag RD. Sympathetic renal pressor responses to centrally infused thyrotropin releasing hormone (TRH) in rats. J Pharmacol Exp Ther 1986; 238: 232-238.

56. Holaday JW. Neuropeptides in shock and traumatic injury: sites and mechanisms of action. In: Neuroendocrine Perspectives, Vol. 1. New York: Elsevier Science Publishers, 1984; 161-199.

57. Holaday JW, D'Amato RJ, Faden AI. Thyrotropin releasing hormone improves cardiovascular function in experimental endotoxic and hemorrhagic shock. Science 1981; 213: 216-218.

58. Hock CE, Lefer AM. Lack of effect of thyrotropin releasing hormone (TRH) in circulatory shock. Peptides $1985 ; 6: 547-553$.

59. Gurll NJ, Reynolds DG, Holaday J, Ganes E. Improved cardiovascular function and survival using thyrotropin releasing hormone (TRH) in primate hemorrhagic shock. Physiologist 1982; 25: 342 .

60. Sirén A-L, Powell E, Feuerstein G. Thyrotropin releasing hormone in hypovolemia: a hemodynamic evaluation in the rat. Am J Physiol 1986; 250; H143-H1101.

61. Holaday JW, Ruvio BA, Faden AI. Thyrotropin releasing hormone improves blood pressure and survival in endotoxic shock. Europ J Pharmacol 1981; 74: 101-105.

62. Reynolds DC, Gurll NJ, Holaday J, Ganes E. Thyrotropin releasing hormone (TRH) in primate endotoxic shock. Physiologist 1982; 25:309.

63. Feuerstein G, Goldstein RE. Effect of PAF on the cardiovascular system. In: Snyder S, ed, Platelet Activating Factor, 1986, In press.

64. Amir S. Anti-anaphylactic action in the mouse of thyrotropin releasing hormone

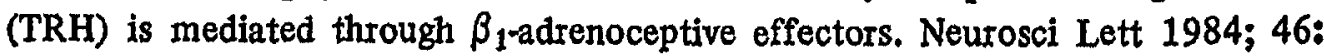
127-130,

65. Amir $S$, Harel $M$, Schachar A. Thyrotropin releasing hormone (TRH) improves survival in anaphylactic shock: a central effect mediated by the sympatho-adrenomedullary $\beta$-adrenoceptive system. Brain Res 1984; 298: 219-224.

66. Lux WE Jr, Feuerstein G, Faden AI. Thyrotropin releasing hormone reverses experimental anaphylactic shock through non-endorphin-related mechanisms. Eur J Pharmacol 1983; 90: 301-302.

67. Lux WE Jr, Feuerstein G, Faden AI. Alteration of leukotriene $D_{4}$ hypotension by thyrotropin releasing hormone. Nature $1983 ; 302(28): 822-824$.

68. Lux WE Jr, Feuerstein G, Faden AI. Thyrotropin releasing hormone reverses the hypotension and bradycardia produced by leukotriene $D_{4}$ in unanesthetized guinea pigs. Prostag Leukot Med 1983; 10: 301-307.

69. Feuerstein G, Lux WE Jx, Ezra D, Faden AI. Reversal of leukotriene $D_{4}$ hypotension by thyrotropin releasing hormone. Neurosci Res $1984 ; 2: 121-124$.

70. Feuerstein G, Lux WE Jr, Ezra D, Hayes EC, Snyder F, Faden AI. Thyrotropin 
releasing hormone blocks the hypotensive effects of platelet activating factor in the unanesthetized guinea pig. J Cardiovasc Pharmacol 1985; 7(2): 335-340.

71. Faden AI, Hallenbeck JM, Brown CQ. Treatment of experimental stroke: comparison of naloxone and thyrotropin releasing hormone. Neurology 1982; 32(10): 1083-1087. 